\title{
Mechanisms with Shape Memory Alloys
}

E. Kibirkštis, R. Liaudinskas, D. Pauliukaitis and K. Vaitasius

Kaunas University of Technology, K. Donelaičio st. 73, 3006 Kaunas, Lithuania

\begin{abstract}
Actuators with elements made from alloys with shape memory have been developed and explored. These actuators may be used in small compressors, in damping systems and in pneumo-vibrotransducers. Some experimental dependencies of mechanical and other physical characteristics of these actuators have been obtained. Equation systems describing the motion of the actuators have been studied. Some characteristics of vibrotransducers, properties and technical parameters of damper were analysed. Examples of technical soliutions are presented and concrete application areas for these actuators in technological processes are indicated.
\end{abstract}

\section{INTRODUCTION}

Drives with links made from materials with shape memory (SM) have been developed and studied at the Transducer Mechanics Research Laboratory of Kaunas University of Technology. These drives are meant for small-size compressors; damping systems and pneumatic vibrotransducers. For the experimental study of such drives special equipment was developed, consisting of several experimental stands, compressed air supply and its control system as well as apparatus for measuring and registering motion parameters of the working organ [1].

\section{STUDY OF PNEUMATIC VIBROTRANSDUCER WITH DRIVE MADE OF MATERIAL WITH SHAPE MEMORY}

The key diagram of the experimental stand for a pneumatic vibrotransducer and the block diagram of measuring equipment is presented in Fig. 1. The experimental stand was used for studying the properties of the vibrotransducer by suddenly changing its chamber volume. For the sudden change of the chamber volume a drive made from material with shape memory was used (see Fig. 1). The dependences of working organ vibration displacement $h$ and vibration frequency $f$ upon compressed air pressure $P_{1}$ have been determined at different geometrical parameters of the system (see Fig. 2).

The obtained dependences show that the vibration displacement decreases (see Fig. 2a) and the vibration frequency increases (see Fig. 2b) when the volume of the transducer chamber is changed (increased); besides, at different tensions the character of the vibration frequency changes (compare curves 1 and 3, Fig. 2b) and the impact of the chamber volume is more clearly expressed (curves 3 and 4, Fig. 2a). 


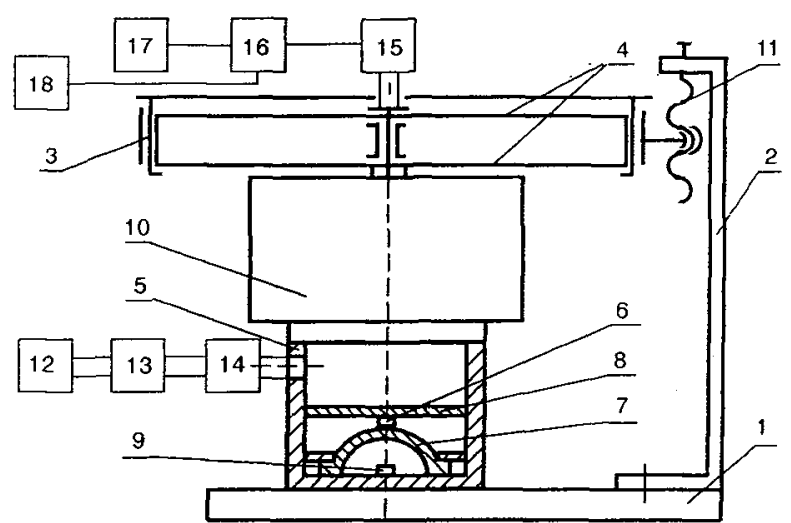

Figure 1: Key diagrams of experimental stand for pneumatic vibrotransducer and block diagram of measuring equipment: 1 - base, 2 - frame, 3 - fixing element, 4 - flat spring, 5 - vibrotransducer chamber, 6 - piston, 7 arc-shaped element made of material with SM, 8 - coding element, 9 - heating element, 10 - variable mass, 11 - screw pair, 12 - compressed air system, 13 - throttle, 14 - manometer, 15 - transmitter, 16, 17 - vibration measuring equipment, 18 - oscillographer

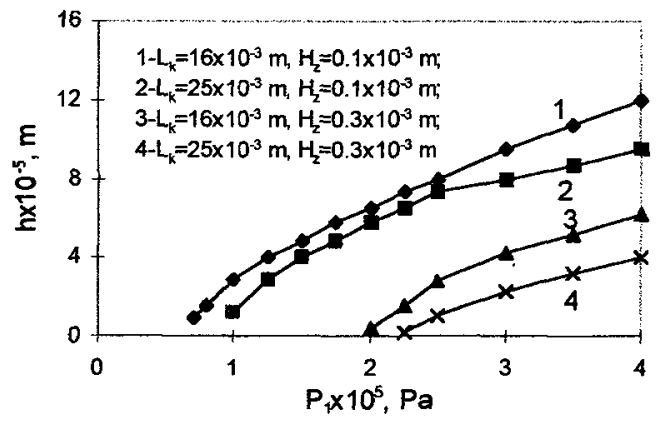

a)

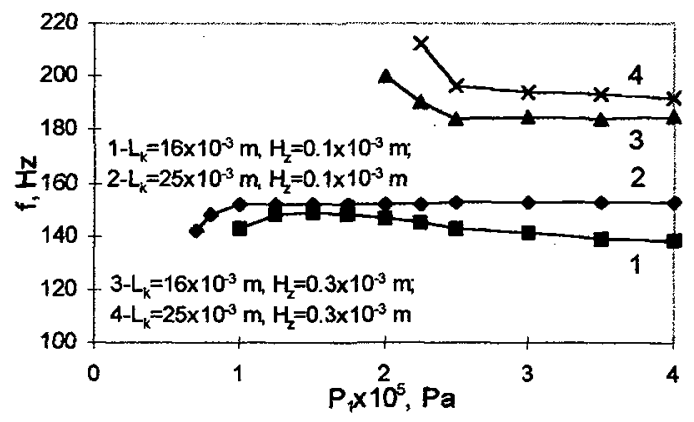

b)

Figure 2: Results of pneumatic vibrotransducer experimental study: dependences of vibration displacement (a) and vibration frequency (b) upon pressure of compressed air supply $\mathbf{P}_{1}$ when the chamber volume is changed: $\Gamma_{1}=1.5 \times 10^{-3} \mathrm{~m}$ - radius of air supply channel, $\mathrm{r}_{\mathrm{k}}=10 \times 10^{-3} \mathrm{~m}$ - radius of chamber; $\mathrm{L}_{\mathrm{k}}$ - height of chamber; $r_{2}=15 \times 10^{-5} \mathrm{~m}$ - external radius, $H_{2}$ - tension, $K_{1}=50 \mathrm{~kg} / \mathrm{s}$ - damping coefficient, $C_{1}=5900 \mathrm{~N} / \mathrm{m}$ - rigidity coefficient, $\mathrm{m}=0.93 \mathrm{~kg}$ - mass of vibrating part

\section{STUDY OF PNEUMATIC DAMPER}

A diagram of a pneumatic suspension with a transducer made from material with shape memory is shown in Fig.3. The pneumatic damping suspension consists of the main chamber 1 connected by throttling opening 3 with damping chamber 2 . The damping chamber contains a drive-transducer made from material with shape memory, consisting of piston 4 , arc-shaped element 5 , as well as cooling and heating elements 8 . The amount of air jet passing through throttle 3 is being adjusted by plate-shape element 6 with SM [2].

In describing the dynamics of the suspension and in working out the mathematical model the following factors were considered:

-the mechanical structure of the suspension,

-hysteresic dependences between temperature and deformations in transducers with SM, 
-impact of mechanical stresses in transducers with SM when temperatures and deformations are changing,

-heat transmission and heat capacity in transducers with SM,

-gas flow processes then occurring in the main chamber and in damping chamber $[3,4]$.

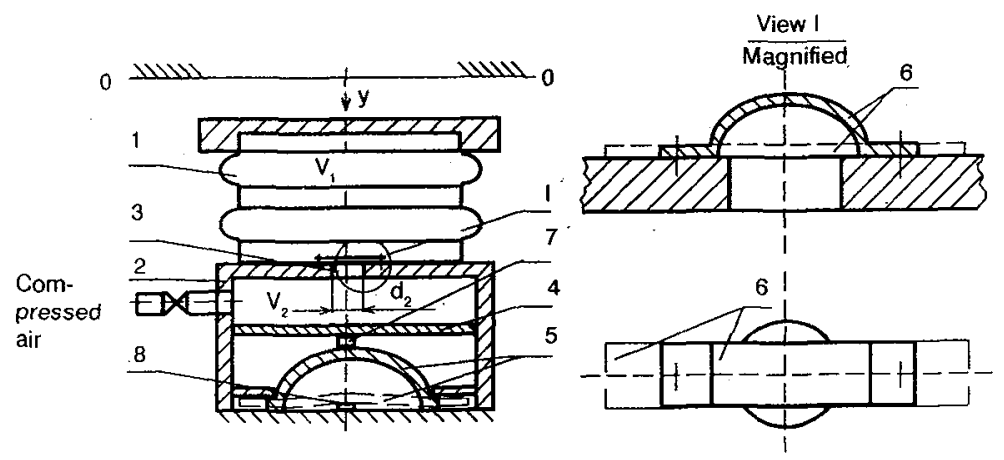

Figure 3: Diagram of pneumatic suspension with SM transducers: 1 - main chamber, 2 - damping chamber, 3 throttling opening, 4 - piston, 5,6 - arc-shaped elements with SM, 7,8 - cooling and heating elements, respectively.

Fig. 4 presents the results of mathematical modelling of a pneumatic support, i.e., the character of vibration settling process of the mass under damping.

When the volume of the damping chamber is being changed from $0.54 \times 10^{-4} \mathrm{~m}^{3}$ to $2.0 \times 10^{-4} \mathrm{~m}^{3}$, the duration of vibration fading out does not change in most cases and the vibration amplitude decreases insignificantly (see Fig. 4). However, it has been noticed that at the throttle diameter $\mathrm{d}_{2} \geq$ $5 \times 10^{-3} \mathrm{~m}$ the area of vibration damping becomes much narrower, i.e., when $\mathrm{V}_{2}=2.0 \times 10^{-4} \mathrm{~m}^{3}$ vibrations are dampered in the pressure range $P_{1}=(1.001 \div 1.5) \times 10^{5} \mathrm{~Pa}$, while at $V_{2}=0.54 \times 10^{-4} \mathrm{~m}^{3}$ the range is reduced to $P_{1}=(1.001 \div 1.01) \times 10^{5} \mathrm{~Pa}$ (throttle diameter $\mathrm{d}_{2}=5 \times 10^{-3} \mathrm{~m}$ ).

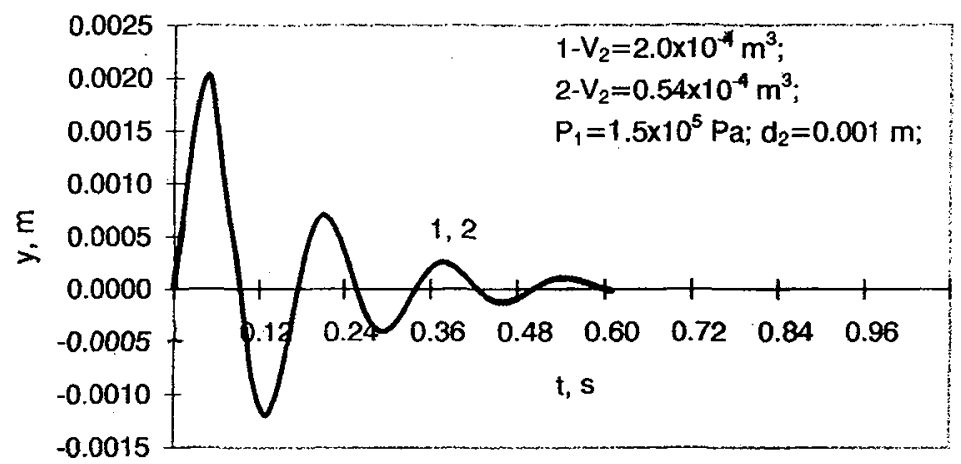

Figure 4: Results of mathematical study of a pneumatic support: the process of vibration settling down of the mass under damping, when the damping chamber volume is being changed, and height of load-carrying chamber $\mathrm{H}_{1}=0.05 \mathrm{~m}$, volume of load-carrying chamber $\mathrm{V}_{1}=1.23 \times 10^{-4} \mathrm{~m}^{3}$, damping chamber volume $\mathrm{V}_{2}=(0.54 \div 2.0)$ $\times 10^{-4} \mathrm{~m}^{3}$, suspension rigidity coefficient $C_{1}=(3100 \div 7100) \mathrm{N} / \mathrm{m}$; resistance coefficient $\mathrm{K}_{1}=(25.6 \div 65.6) \mathrm{kg} / \mathrm{s}$, load-carrying chamber cross-section area $S_{1}=0.1452 \times 10^{-2} \mathrm{~m}^{2}$, throttle cross-section area $S_{2}=0.6 \times 10^{-7} \mathrm{~m}^{2}$; cross-section area of throttle holes $S_{3}=7.85 \times 10^{-7} \div 7.85 \times 10^{-5} \mathrm{~m}^{2}$; initial velocity of elastic plate motion $V_{0}=0.1$ $\mathrm{m} / \mathrm{s}$, mass of upper elastic plate $M=2.8 \mathrm{~kg}$; throttle length $L=3 \times 10^{-3} \mathrm{~m}$; pressure of supplied air $P_{1}=(1.001 \div$ 3.0) $\times 10^{5} \mathrm{~Pa}$ 


\section{POSSIBLE APPLICATIONS OF DRIVES WITH SHAPE MEMORY}

An example of possible application of a drive with shape memory is given in Fig. 5.It is a small-size piston compressor which consists of bellow-shape piston 1 which is installed in a cylinder (not shown in the figure) and to which drive element 2 with shape memory is fixed. The other end of the element is fixed to the case. Drive 2 is contacting with cooling 4 and heating 3 elements. Suction valve 5 and pressure valve 6 are installed in the cylinder. In the position presented in the figure plate 3 is being heated. The heat is transmitted to the arc of element 2 . When the arc material reaches the temperature of reverse martensitic transformation it starts bending in the apposite direction (towards mirror reflection, marked by a dotted line in the drawing). When the arc straightens up, the cycle of gas pressure and discharge starts in the cylinder by piston through valve 6 . When it bends away from the upright position, suction cycle through valve 5 starts. When the arc shifts to the opposite position, its cooling takes place. When the arc material reaches the temperature lower than the temperature of phase transformation, the arc gets back to the former position. When the arc reaches the straight position, air is compressed, and after a certain period air is sucked in. Then the cycle is repeated.

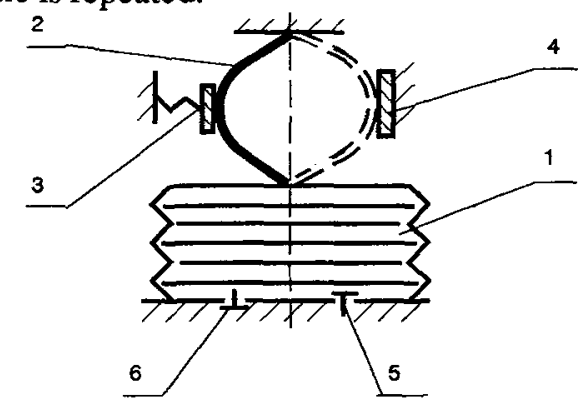

Figure 5: Diagram of small-size piston compressor: 1 - piston, 2 - drive element 2 with SM, 3 - heating elements, 4 cooling element, 5,6 - suction valve and pressure valve

The authors have also developed drives for other purposes where materials with shape memory are used. Functional possibilities of applying such mechanisms in different technologies are very wide, however, their application is not always reasonable economically.

\section{References}

[1] Kibirkštis E., Vaitasius K. Experimental Study of Multifunctional Pneumatic Self-Exciting Transducers./Ninth World Congress on the Theory of Machines and Mechanisms. Politecnico di Milano, Italy. August 29/September 2, 1995. Proceedings. Vol 4. P.P. 2693 - 2697.

[2] Kibirkštis E., Pauliukaitis D., Liaudinskas R. Study of mechanical dempfering system./XVI Symposium "Vibrations in physical systems". Poznan-Blažejevko, Poland. 22-25 May, 1996. Abstracs, p.p. 154-155.

[3] Kibirkštis E. Pneumatic self-excited vibrodrives of testing machines for the study of mechanical properties of materials and constructions Taikomoji mechanika./Mokslo darbai. Nr. 1.- Kaunas, Technologija, 1991. 24 - 34 p.

[4] Kibirkštis E., Vaitasius K. Transporto priemonių pneumatinès pakabos tyrimas. Konferencijos "Transporto priemonés - 95" medžiaga. Kaunas, Technologija, 1995, 56 - 61 p.

[5] Kibirkštis E., Vaitasius K., Kiškis V., Ruzgys M. Invention (SU) Nr. 1543116, F 04 B 35/00, $19 / 24$. 